\title{
Formación ciudadana en la infancia: reflexiones desde la revisión teórica
}

Citizenship Education in Childhood: Reflections from a Theoretical Review

Artículo de reflexión | Reflective articles

Fecha de recepción: 31 de enero de 2020

Fecha de aceptación: 14 de abril de 2021 Fecha de disponibilidad en línea: octubre de 2021

doi: 10.11144/Javeriana.m14.fcir

Luz Marina Lara-Salcedo laral@javeriana.edu.co

Pontificia Universidad Javeriana, Colombia (D) ORCID: https://orcid.org/0000-0003-0182-6878

Neftali David Suarez-Rivero nsuarez@javeriana.edu.co Pontificia Universidad JaVeriana, Colombia D ORCID: https://orcid.org/0000-0002-2307-7233

Para citar este artículo | To cite this article Lara-Salcedo, L. M. \& Suarez-Rivero, N. D. (2021). Formación ciudadana en la infancia: reflexiones desde la revisión teórica. magis, Revista Internacional de Investigación en Educación, 14, 1-24. doi: 10.11144/Javeriana.m14.fcir 


\title{
Resumen
}

Se brinda un conjunto de reflexiones teóricas que aportan al campo conceptual de la ciudadanía para su práctica en el espacio escolar. Parte de explorar las nociones clásicas y contemporáneas del concepto, y luego se analizan algunas tendencias de la formación ciudadana para ubicar el tipo de ciudadanía que es necesario promover con los niños, a la luz de las pedagogías críticas y de una reconstrucción crítica del concepto. Finaliza señalando la urgencia de formar en ciudadanía desde la infancia, de su reconocimiento como ciudadanos y sujetos políticos, con una mirada renovada de la educación ciudadana desde una perspectiva crítica, decolonial y más incluyente.

\section{Palabras clave}

Ciudadanía; educación ciudadana; democracia; infancia; enfoque crítico

\begin{abstract}
A set of theoretical reflections are provided that contribute to the conceptual field of citizenship for its practice in the school setting. This paper starts by exploring the classic and contemporary notions of the concept, then analyzes some trends in citizenship education to locate the type of citizenship to be promoted with children, in the light of critical pedagogies and a critical reconstruction of the concept. The paper ends by pointing out the urgency of educating in citizenship from childhood, of their recognition as citizens and political subjects, with a renewed view of citizenship education from a critical, decolonial, and a more inclusive perspective.
\end{abstract}

\section{Keywords}

Citizenship; citizenship education; democracy; childhood; critical approach 
Descripción del artículo | Article description

Artículo de reflexión derivado del proyecto de investigación

Configuración de prácticas educativas innovadoras en

formación ciudadana. Estudios de caso en cinco experiencias

significativas en el desarrollo de competencias ciudadanas

identificadas por el MEN.

\section{Introducción}

Este artículo de reflexión teórica se deriva de la investigación Configuración de prácticas educativas innovadoras en formación ciudadana. Estudios de caso de cinco experiencias significativas en el desarrollo de competencias ciudadanas identificadas por el Ministerio de Educación Nacional (MEN)1. Su propósito es compartir uno de los resultados derivados de la investigación, relacionado con la construcción de un marco de reflexión teórico sobre la ciudadanía y la formación ciudadana como punto de partida, para llegar a la discusión sobre los nuevos retos que las sociedades plurales demandan hoy día en términos de formación ciudadana a los maestros² ${ }^{2}$ y que están relacionados con una educación para la ciudadanía desde pedagogías feministas, críticas y decoloniales. La metodología para este artículo consideró dos momentos: el primero a partir de un proceso de revisión teórica sobre ciudadanía y producción sobre educación para una ciudadanía, para luego bordearla a partir de enfoques críticos, decoloniales y feministas. En un segundo momento se llevó a cabo un proceso analítico y reflexivo sustentado en las fuentes consultadas que soportan este artículo, con el fin de aportar a una práctica educativa que reconozca esas otras ciudadanías.

Así, se propone una articulación con la transformación de la concepción de ciudadanía y la formación ciudadana. Además, el estudio se vincula con la institución escolar al situar las reflexiones sobre la ciudadanía en el contexto educativo, analizando la formación que se debe promover para su consolidación. Posteriormente se llega a la categoría de infancia, la cual se aborda desde las transformaciones que se proponen para la formación ciudadana, a partir de una educación con enfoque crítico que posibilite su reconocimiento

1 La investigación fue un estudio de caso múltiple con enfoque descriptivo-comprensivo, que buscó describir los rasgos de cinco experiencias significativas para comprender los sentidos y significados que los maestros le otorgan a la formación ciudadana. El artículo recoge diversas líneas de conocimiento sobre ciudadanía, para repensar la formación ciudadana desde la educación inicial en el contexto actual que reclama el reconocimiento de nuevas ciudadanías.

2 Para efecto de la presentación de este artículo y en aras de utilizar un lenguaje inclusivo, utilizaremos el artículo "los" para referirnos a las identidades "las", "los", como también a las identidades no binarias "les". 
como agentes activos en la construcción de sociedad, y se finaliza con los sentidos de otra educación ciudadana más justa e incluyente.

La ciudadanía afecta a todos, probablemente porque, como lo plantea Aristóteles (1993), el hombre es un animal cívico, pues su forma básica y, quizás, esencial de estar-en-el mundo es la de pertenecer a una ciudadanía, por lo que nadie escapa a la condición de ciudadano. Sin embargo, nuestras consideraciones o maneras de entenderla son moldeadas a priori por el contexto cívico en el que nos encontramos. Es decir, el mundo al que venimos y con el que nos encontramos para desplegarnos como humanos nos moldea cívicamente. Por lo tanto, el vaciado resultante no es nunca perfecto ni satisfactorio, ya sea porque muchos no encajan cómodamente o no tienen cabida en él, porque no está hecho para ellos o porque solo lo está parcialmente. Entonces, la ciudadanía es un espacio de descontento, dinámico y transformado activamente, resistiéndose a una rígida estructuración.

Ante este panorama, el artículo propone una reflexión que se desarrolla en cuatro apartados, así: en el primero, se analiza la construcción de ciudadanía como un escenario de tensiones y disputas. En el segundo, se reflexiona en torno a la identidad y el sentido de pertenencia como entradas a la ciudadanía. En el tercero, se indaga por la educación ciudadana y a qué tipo de ciudadanía sirve. Finalmente, en el cuarto, se analiza la necesidad de transitar del ciudadano siervo al emancipado, a la luz de las pedagogías críticas y los planteamientos de autores como O’Donnell (1999; 2003), de Sousa-Santos (1998; 2004; 2005; 2006a; 2006b; 2008), Aguiló (2009), Ramos et al. (2020) y Martínez et al. (2017), para cerrar con los retos y los desafíos para formar en ciudadanías de alta intensidad desde la infancia.

\section{La construcción de ciudadanía: un escenario de tensiones y disputas}

La ciudadanía es un concepto que desempeña un papel central, tanto en la teoría como en la práctica política. Esta centralidad, sin embargo, no implica univocidad. Por el contrario, es uno de los conceptos que más concepciones ha resistido en la historia, a tal punto que un estudioso del asunto ha señalado que "el mayor problema del término 'ciudadanía' es que carece de concepto, tan sólo podemos hablar de concepciones" (ZapataBarrero, 2001, p. 6).

La razón probable de este incómodo rasgo reside en que es un concepto que, al expresar la relación entre el Estado y los individuos, ha servido de línea divisoria entre la inclusión y la exclusión. Es decir, ha fungido como criterio estatal para definir quiénes son parte y quiénes no. Así, en una 
caracterización más radical, se trataría, como lo expresa Zapata-Barrero (2001, siguiendo a Whelan, 1981), de una noción excluyente, cuya "semántica ha connotado constantemente un privilegio y un límite social, ético, político y económico frente a las demás personas no incluidas dentro de su alcance semántico" (pp. 8-9).

En este sentido, resulta natural que la noción de ciudadanía sea expresión de un campo de batalla ideológico, definido por medio de un trazado de fronteras semánticas. De este modo, su definición es dinámica, ya que algunas fuerzas tiran hacia su ampliación o reducción, mientras que otras enfatizan en su conservación. Entonces, su estabilidad, reflejada en la relativa permanencia de una noción específica, es solo cuestión de tiempo.

Así, los grandes períodos históricos (clásico griego, clásico romano, cristiandad, etc.), caracterizados por cierta estabilidad cultural y política, pudieron gozar de concepciones relativamente unánimes de la ciudadanía, mientras no se vieron retados por la presión ejercida tanto por los cambios económicos, paulatinamente acumulados en las mismas sociedades que les servían de enclave, como por la irrupción violenta de otras fuerzas externas (como impulsos políticos relacionados con la aparición de la República, la irrupción y consolidación de las monarquías o la misma Revolución francesa). Cualquiera de estos fenómenos producidos por la dinámica intrínseca de la historia se expresa no solo en la transformación de los Estados, sino, también, en lo que es su correlato esencial, la ciudadanía, cuya definición se modifica cuando un actor social nuevo (llámese clase, pueblo, etnia, movimiento social o grupo identitario) asume la demanda consciente de su derecho a ser incluido. Estos procesos de lucha por la inclusión o el rechazo, los cuales tienen como punto de llegada y partida determinadas acuñaciones jurídicas que definen al ciudadano, se acompañan de una confrontación de visiones, modelos y construcciones ideológicas.

La modernidad europea, particularmente desde la llustración hasta lo que podría denominarse "período contemporáneo", representa un cambio fundamental en el concepto de ciudadanía. Durante esta época su definición es despojada, por lo menos desde un punto de vista jurídico, de los elementos definitorios excluyentes, como la pertenencia a un status social privilegiado, del cual no participan todos en una misma jurisdicción estatal. De este modo, solo dos criterios se mantienen en la construcción del concepto, el de nacionalidad (pertenencia al mismo Estado-nación) y el de igualdad (todos los que son nacionales gozan de los mismos derechos) (Zapata-Barrero, 2001).

Esta noción expansiva de ciudadanía implica, en la práctica política, diversos avatares y conflictos. A su vez, es un vehículo de intereses que ideológicamente se les ocultaron y enmascararon a los mismos paladines 
ilustrados de la libertad y la igualdad. Ello se evidencia en la temprana crítica de Marx a la separación entre el hombre y el ciudadano, en la nueva formulación liberal de los derechos humanos y en la manera como el Estado (que solemnemente los promulga) se sostiene sobre una realidad de exclusión y una falsa apariencia de comunidad:

Allí donde el Estado político acabado [se refiere al modelo de Estadonación liberal] ha alcanzado su verdadero desarrollo, el hombre lleva, no solo en el pensamiento, en la conciencia, sino en la realidad, en la vida, una doble vida, celestial y terrenal, la vida en la comunidad política, en la que se considera como ser comunitario, y la vida en la sociedad burguesa, en la que actúa como particular, considera a los otros hombres como medios, se degrada a sí mismo como medio y se convierte en juguete de poderes extraños. (Marx, 2008, p. 180)

En este pasaje de intención crítica se muestra la tensión entre el carácter jurídico formal e ideológico de la igualdad (en palabras de Marx, la comunidad política, la fórmula estatal, en la que los individuos son considerados como personas iguales y protegidas sin distingos en sus derechos) y el carácter real de las desigualdades, las cuales están mediadas por el derecho de propiedad, erigido como derecho-medida de los demás y no solamente considerado como uno más entre los otros derechos humanos reconocidos por el Estado. Como es sabido, esta crítica a la separación entre la igualdad formal o ciudadanía ideal, expresada en los derechos civiles, y la desigualdad real, mediada por el mercado, conduce en la línea social-democrática a la expansión de los derechos humanos o complementación de los derechos civiles y políticos con los económicos, sociales y culturales.

Este proceso de reconocimiento de nuevos derechos, frente a los ya admitidos por los Estados liberales de derecho, permitió a T. H. Marshall (1950), en su aclamado ensayo Citizenship and Social Class, enunciar una directa relación en clave evolutiva entre ciudadanía, derechos humanos e inclusión. En su descripción muestra las luchas sociales y políticas entre los siglos XVIII al XX, mediante las cuales se formularon y extendieron los distintos tipos de derechos que componen la ciudadanía moderna, y que estos derechos responden a las conquistas logradas por la lucha de clases, como nos lo enseña la historia de los movimientos sociales.

De acuerdo con Habermas (1994, p. 30): "El análisis de Marshall defiende la tesis de que el estatus de ciudadano en las sociedades modernas se ha visto paulatinamente expandido y fortalecido". Así, las fases sucesivas, que para Marshall (1950) implican la ampliación de la ciudadanía como inclusión, son las tres que marcan la evolución de los derechos humanos en 
el proceso de modernización europeo: derechos civiles, políticos y sociales. Acudiendo a la terminología empleada por este sociólogo, la ciudadanía se amplía, entonces, desde un primer núcleo, denominado ciudadanía civil, para abarcar una política y terminar comprendiendo, por último, una social. Estas esferas de ampliación unidas componen una ciudadanía plena. Por consiguiente, cada uno de estos niveles o esferas de inclusión implica en su momento histórico un paso ulterior hacia la igualdad.

De este modo, los derechos civiles, entendidos como libertades negativas (es decir, del individuo frente a la esfera de actuación del Estado), como son la libertad de expresión, de conciencia y religiosa, así como el derecho de establecer contratos válidos, entre otros, implican una igualdad formal, como ya lo había puesto de manifiesto Marx un siglo antes. Dicho en términos más intuitivos, todos los ciudadanos son protegidos por la ley frente a las injerencias del Estado en su libertad de contratar, pensar o elegir sus creencias religiosas.

Sin embargo, aceptar la igualdad ante la ley en estos términos no implica necesariamente aceptarla en cuanto a la elección de los legisladores. Entonces, si bien la ciudadanía civil conduce, en su lógica interna, al reconocimiento de una ciudadanía política, ello no significa que la incluya de facto. Así lo ilustra, por ejemplo, el caso de las mujeres y el sufragio, pues, en épocas en las que no les era reconocido el derecho al voto, aunque gozaran formalmente de muchos de los mismos derechos civiles que los hombres, su exclusión del espacio de participación en el sufragio las excluía de la creación de las leyes. De este modo, aunque iguales ante la ley, eran desiguales en torno a la elección de quién la establecía.

El sufragio universal, correspondiente a la ampliación de la ciudadanía con el reconocimiento de los derechos políticos, implica en el contexto de la primera mitad del siglo XX el derecho al voto político de las mujeres y los obreros. Esta ampliación del concepto de ciudadanía abre simultáneamente la puerta para la expresión de otro nivel de desigualdad que, aun bajo las condiciones de representatividad en los procesos de creación legislativa, encarna un obstáculo para la plena inclusión y la igualdad real: las desigualdades en materia social.

La demanda por el acceso igualitario a bienes, servicios y prestaciones (como la salud o la educación) marca un nuevo paso para la construcción de la ciudadanía. La desigualdad en términos de propiedad o riqueza trae de suyo una disparidad en materia de bienestar. Así, la ciudadanía social, en palabras de Marshall (1950), va a implicar, entonces, el disfrute de todo un conjunto de derechos que van "desde el de contar con una porción de bienestar económico y de seguridad hasta el de participar de toda la herencia social y vivir la vida de un ser civilizado, de conformidad con los estándares 
prevalecientes en la sociedad" (p. 11). Estos derechos (conocidos como económicos, sociales y culturales) encuentran su sede en el Estado de bienestar.

De este modo, el cuadro relacional y evolutivo entre derechos y ciudadanía se hace corresponder en Marshall (1950) con una definición de esta como "status otorgado a los que son miembros de pleno derecho dentro de una comunidad" (se sobreentiende que política) y añade que "todos los que poseen ese status son iguales respecto de los derechos y deberes que [dicho status] les confiere" (Marshall, 1950, pp. 28-29). El obstáculo principal de esta definición, o si se quiere noción, es su fuerte anclaje en la "comunidad política", es decir, en el Estado.

Entonces, por ejemplo, el problema de las migraciones, por referir solo el más escandaloso, pone claramente de manifiesto las dificultades de esta concepción, en la que la plenitud de derechos y deberes, de la cual se hace acreedor el ciudadano, depende de la membresía o pertenencia a un Estado. Como lo ha hecho notar Ferrajoli (1999), este anclaje de los derechos humanos en la ciudadanía o, lo que para la concepción marshalliana es lo mismo, en la pertenencia o membresía a una comunidad política pone en riesgo el carácter universal de los derechos humanos y, al mismo tiempo, reduce el compromiso de los Estados de cara al reconocimiento de estos solamente a aquellos que son ex lege sus nacionales.

Así, de acuerdo con el mencionado jurista italiano, Marshall (1950) incurre en un error, pues no advierte que los derechos humanos, reconocidos como fundamentales en las constituciones modernas, tienen una doble caracterización: como derechos humanos y derechos del hombre y del ciudadano, homme et citoyen, en la clásica formulación de la Revolución francesa (1789). Entonces, como derechos humanos, corresponden a toda la humanidad y, en tanto derechos del hombre y del ciudadano, son otorgados en calidad de miembro a cada uno de los integrantes de una comunidad política determinada. Por lo tanto, la confusión de Marshall (1950) radica en limitar la totalidad de los derechos a la pertenencia a una comunidad política, sobre todo al denominarlos derechos de ciudadanía. De este modo, el derecho, por ejemplo, a la libre movilidad es un derecho humano que ningún Estado, en principio, tendría la potestad o arbitrio de constreñir.

Sin embargo, es necesario reconocer que el error de Marshall (1950) obedece a una coyuntura histórica. En primer lugar, a su intención de afianzar, en el contexto británico de la segunda post-guerra, el Estado del bienestar. En segundo lugar, a que los retos actualmente palpables no eran visibles en ese momento, pues "en los tiempos de Marshall todavía los procesos de globalización y de integración mundial y los fenómenos migratorios no habían llegado al punto de poner en estridente contradicción los 
derechos del hombre y los derechos del ciudadano" (Ferrajoli, 1999, p. 56). Además, en tiempos de Marshall (1950) podría tener sentido ver los derechos hoy comprendidos en los dos pactos de 1966: Pacto Internacional de Derechos Civiles y Políticos (ONU, 16 de diciembre de 1966a) y Pacto Internacional de Derechos Económicos, Sociales y Culturales (ONU, 16 de diciembre de 1966b), como derechos atribuidos a los individuos por un Estado, por el hecho de ser miembros de la comunidad política bajo su jurisdicción. No obstante, en la actualidad, se trata de derechos a los cuales los Estados, precisamente por la vía de su ratificación formal, han asumido como obligaciones ante la sociedad internacional.

De este modo, tanto los derechos civiles como muchos de los políticos y la mayor parte de los sociales son derechos humanos y no del ciudadano. Así, en la interpretación que Ferrajoli (1999) les atribuye, se establece un tránsito histórico entre derechos status civitatis (o ciudadanía) a status personae (personalidad o subjetividad jurídica). Esta transición no descansa en una noción iusnaturalista, sino positiva, al ser derechos reconocidos legal y soberanamente por los mismos Estados a partir de convenios internacionales, como miembros de pleno derecho en la sociedad internacional.

Con base en estas premisas, que tienen como eje articulador la señalada crítica a la noción de Marshall (1950), Ferrajoli (1999) insta a superar la confusión mediante lo que estima es la opción para tomarse en serio los derechos humanos:

Tomar en serio estos derechos significa hoy tener el valor de desvincularlos de la ciudadanía como "pertenencia" (a una comunidad estatal determinada) y de su carácter estatal. Y desvincularlos de la ciudadanía significa reconocer el carácter supra-estatal —en los dos sentidos de su doble garantía constitucional e internacional-y por tanto tutelarlos no solo dentro sino también fuera y frente a los Estados, poniendo fin a este gran apartheid que excluye de su disfrute a la gran mayoría del género humano contradiciendo su proclamado universalismo. (p. 117)

Como se evidencia, el reconocimiento y el ejercicio de los derechos humanos no pueden depender de un concepto de ciudadanía. Por el contrario, es la ciudadanía la que descansa sobre el reconocimiento de los derechos humanos.

\section{Identidad y sentido de pertenencia: bondades y riesgos en la formación ciudadana}

En términos generales, puede afirmarse que existen dos perspectivas sobre la ciudadanía: una liberal, que enfatiza en la dimensión legal o jurídica, 
y otra republicana, que pone el acento en la agencia política. Estas marcan una diferencia fundamental en términos del modelo de ciudadanía o de ciudadano que se privilegia en un proceso educativo consciente ${ }^{3}$.

Sin embargo, hay una tercera dimensión que puede ser considerada de forma independiente a las dos lecturas anteriores, la identitaria. De hecho, en cualquier consideración de la democracia están inmersas estas tres dimensiones: la legal, la política y la relativa a la identidad (Leydet, 2014). En palabras de Cohen (1999), se trata de tres componentes del principio de ciudadanía (entendido aquí como dimensión desde la cual se fundamenta el concepto) que cabe identificar en la literatura: un estatus legal de la personalidad jurídica, un principio político de la democracia y una forma de pertenencia e identidad política (Cohen, 1999).

Esta tercera dimensión (la identidad), aunque implícita en los dos grandes modelos de ciudadanía (liberal y republicano), es decisiva cuando se quiere contribuir conscientemente por medio de la educación al fomento de un tipo determinado de ciudadano. Así, para Leydet (2014), la dimensión asociada a la identidad, o sentimiento de pertenencia, es la menos simple de las tres, pues está inmersa en los discursos tanto liberales como republicanos bajo el rótulo de diferentes aspectos relacionados con los niveles individuales y colectivos de la vida y con factores de integración social.

Al respecto, obsérvese que los dos enfoques iniciales no discuten de forma explícita la identidad ciudadana, pues la dan por supuesta, ya sea como algo que antecede al vínculo ciudadano-Estado (y que es luego asegurado jurídicamente) o como algo que se configura a partir de la actividad política de los ciudadanos por vía de su constitución o auto-determinación como comunidad política. Esto tiene fuertes incidencias en la ciudadanía, pues si la identidad es concebida en clave pre-política puede derivarse de ello un etnonacionalismo. Mientras que si se la concibe en clave constructivista, a partir de la agencia política, se tiene, en un extremo,

3 Desde el punto de vista de la primera interpretación [esto es, la liberal] la ciudadanía es concebida en analogía con el modelo de una membresía recibida dentro de una organización que le asegura un status legal. Desde la perspectiva de la segunda, se la concibe análoga al modelo de una membresía realizada en una comunidad ética que se auto-determina. En la primera, los individuos permanecen externos al Estado, contribuyendo solo de cierta manera en su reproducción a cambio de los beneficios que les proporciona esa membresía organizacional. En la segunda, los ciudadanos se integran en una comunidad política como partes en un todo, esto es, de tal manera que pueden no solo formar su identidad personal y social en ese horizonte de tradiciones compartidas e instituciones reconocidas intersubjetivamente. En la primera, los ciudadanos no se diferencian de las personas privadas que portan sus intereses pre-políticos para hacerlos valer vis-à-vis el aparato estatal, mientras que, en la segunda, la ciudadanía solo puede realizarse como la práctica conjunta de la auto-determinación (Habermas, 1994). 
una identidad configurada mediante el proceso democrático que habilita (con la formación de la voluntad política y la comunicación pública) un "patriotismo constitucional" (Habermas, 1999, p. 94) o, en el otro extremo, un populismo abierto a la negación misma de los principios constitucionales de derecho.

En este sentido, el foco sobre la identidad como sentimiento de pertenencia es fundamental para la vitalidad de la democracia. Como hacen notar Kymlicka y Norman (1997):

[...] la salud y estabilidad de una democracia moderna dependen no solo de la justicia de su 'estructura básica', sino también de las cualidades y actitudes de sus ciudadanos: por ejemplo, de su sentido de identidad y de cómo perciben las formas potencialmente rivales de identidad nacional, regional, étnica o religiosa. (p. 352)

De este modo, el papel de la identidad o del sentido de pertenencia es sobre todo valorado por los teóricos de la sociedad civil, vertiente del pensamiento comunitarista que "al tiempo que enfatiza la necesidad de la civilidad y del dominio de sí mismo para una democracia saludable, le niega al mercado o a la participación política la capacidad de enseñar tales virtudes" (Kymlicka y Norman, 1997, p. 363). Una pregunta que plantea este enfoque, a guisa de desafío frente a la aproximación liberal, es a cuál institución se le podría cargar la tarea y la correspondiente responsabilidad de formar las virtudes de la civilidad y del dominio de sí, cuya respuesta apunta a las organizaciones de la sociedad civil. La razón de ello estriba en el carácter voluntario que reviste a dichas organizaciones. Es decir, se trata de asociaciones que el individuo elige libremente, por convicción, simpatía o contagio, por un deseo de pertenecer o "hacer parte de" esa comunidad que ejerce sobre la persona una atracción particular y profunda, extraña a las motivaciones del cálculo.

Uno de los principales defensores de esta visión de la ciudadanía y su formación asociada a la pertenencia activa es Michael Walzer (1970). Para él, la ciudadanía deja incluso de verse como un concepto monolítico, pues se es simultáneamente ciudadano en varios sentidos: como partícipe de una organización pequeña (local), como puede ser una secta o una organización política; como miembro de un Estado nacional; o como perteneciente a la familia humana, esto es, como ciudadano del mundo. Las diferencias entre una y otra de estas esferas consiste no únicamente en su tamaño, sino, también, en el nexo funcional. Además, el vínculo esencial de la ciudadanía y al mismo tiempo su criterio es la obligación. 
La época actual es singularmente turbulenta en este sentido. Ello dado que, por un lado, es hereditaria de la tradición democrático-liberal, responsable de haber ampliado a su máxima expresión el concepto de ciudadanía, confiriéndole, por medio de los derechos humanos, un significado de inequívoca connotación universalista. Por otro lado, al ser el escenario del proceso de mundialización económica y de los cambios socio-culturales que esta ha traído al ámbito tanto global como doméstico de los Estados.

Este último proceso, conocido con el nombre genérico de globalización, tiene dos caras. Por un lado, una clara connotación universalista que pareciera favorecer el auge de una ciudadanía global íntegra. Por otro, como lo atestigua la actual crisis de los migrantes a gran escala, una tendencia a la xenofobia y el retroceso de muchos Estados a políticas de cierre de fronteras y abierta propaganda nacionalista.

Es en este escenario mundial donde la educación ciudadana no solo adquiere una fundamental importancia, sino deviene, también, como un espacio de propuestas encontradas, un terreno, además, peligroso, en el que el choque de las nociones indicadas se hace inevitable. Ante ello, el reto que enfrenta la educación ciudadana está en pensar una propuesta de ciudadanía para muchos y no para algunos, orientada hacia la inclusión política, social y multicultural, con mayores condiciones de equidad y justicia social.

\section{Ciudadanía: ¿aprendizaje cívico, desarrollo de competencias o formación del sujeto político?}

Abowitz \& Harnish (2006) han Ilamado la atención sobre cómo las diferentes nociones de ciudadanía afectan la práctica política. Así, la forma en la que se ejerce la ciudadanía está siempre condicionada, si no de manera inmediatamente visible, por un modo de entender, que, a su vez, estaría develando una noción determinada, sea esta liberal o republicana, cosmopolita o estrechamente nacionalista, democrática o restrictiva. El problema estriba, según lo entienden estos autores, en que la ciudadanía comprende cinco aspectos diferentes:

(1) un estatus de membresía que detentan los individuos dentro de una unidad política dada; (2) una identidad que les es conferida a los individuos en virtud de su pertenencia a dicha unidad política; (3) un conjunto de valores que son por regla general interpretados como un compromiso con el bien común o con una unidad política particular; (4) la práctica de un grado de participación en el proceso de la vida política; y (5) el uso de un conocimiento y comprensión de las leyes, documentos, estructuras y procesos de gobierno. (Enslin, 2000, citado en Abowitz \& Harnish, 2006, p. 653) 
Estos cinco elementos, si bien son compatibles en su lectura y, consecuentemente, en su práctica, pueden diferir y ser motivo de conflictos sociales de acuerdo con la manera como se entienda cada uno, es decir, dependiendo del contenido moral y político que se les atribuya como significado. Por ejemplo, la membresía o sentido de pertenencia a una comunidad política tiene sentidos antagónicos para un liberal o un republicano, según puede inferirse de lo ya expuesto.

De igual forma, la identidad, ubicada en el segundo lugar de la numeración, está supeditada a determinados procesos históricos vividos por el sujeto particular y a las formas en que los individuos que integran una comunidad se han visto representados o sub-representados. De este modo, las feministas y los estudios post-coloniales han puesto de manifiesto cómo ciertas identidades, como la de ser mujer o afrodescendiente, implican una agencia subvalorada, que no es reconocida, sino negada mediante su inclusión/exclusión en una identidad hegemónica, que es la del varón, el blanco o el occidental.

Igual de problemático es el tercer elemento mencionado, los valores interpretados como un compromiso con el bien común. La única forma en que dejaría de ser un problema es que nadie defina los valores ni revele el referente que le sirve de interpretante: historia, formas en que esta se ha experimentado y plasmado en las instituciones vigentes, las narrativas imperantes y las silenciadas, las integradas a la historia oficial y las relegadas a las memorias resistentes.

En el grado de participación política, si bien es quizá el menos problemático de los cinco (y ya se había aludido al lugar que el pensamiento republicano le adjudica), las corrientes posestructuralistas han puesto en entredicho que la participación sea per se un escenario que garantice que las subjetividades se formen y emerjan de forma espontánea en un libre juego de intersubjetividad democrática e igualitaria, un teatro neutral en el que las voces se expresan de forma transparente. Por el contrario, la participación democrática en el juego político tiene su a priori histórico, institucional que, en términos más generales, aunque menos visibles, determina las reglas ocultas, pero poderosas, de lo que se dice, cómo, quién, qué se autoriza o desautoriza.

El último elemento relacionado por Abowitz \& Harnish (2006) parece ser, por su desnudez, el que menos problematicidad enigmática oculta. ¿Quién estaría en desacuerdo con que la ciudadanía, en tanto ejercicio activo o inmunidad pasiva, es un poder que habilita o un legado que beneficia y se actualiza en virtud de su conocimiento? Por su directa relación con el conocimiento de las leyes de gobierno, los textos en los que se establecen los poderes-derechos y los procedimientos que los legitiman, este quinto 
rasgo de la ciudadanía es el que más profusamente y sin cuestionamiento se ha articulado con la educación cívica.

Sin embargo, ese mismo carácter de verdad auto-evidente en la que reposa este último elemento es el que más sospecha debería despertar, pues todo el conocimiento que presupone el ejercicio de la ciudadanía no es la descripción de un estado de cosas, sino su postulación ideal dentro de un tipo de orden político dado. Es decir, todo el saber que aquí se enuncia como rasgo de la ciudadanía remite en último término a un orden normativo que, de alguna manera, implica los viejos binomios de sistema y agente, orden social y sujeto social, Estado y ciudadano. Es decir, todo orden que se postula normativamente incluye la aspiración de un sujeto ideal, aquel que se desea construir desde el referente del mismo orden postulado normativamente. Dicho en su forma más abstracta, se postula el buen ciudadano, pero, ¿cómo surge ese postulado?, ¿cuáles son las reglas de su constitución?, ¿cómo se construye ese ideal de sujeto, si se asume que es desde la temprana niñez y a lo largo de todo el proceso de socialización hasta su realización adulta?, ¿qué medios se utilizan para ello? Parece ocioso responder a cada una de estas preguntas, cuando se han producido miríadas de textos para ello. Sin embargo, es imperativo recordar que fue Paulo Freire, desde su pedagogía del oprimido, quien primero llamó la atención sobre el poder moldeador que la educación puede ejercer sobre el educando, al punto de hacer de él un sujeto pasivo, construido o domesticado a la medida de un sistema de opresión que espera esto de él.

Entonces, la ciudadanía como un aprendizaje en clave de adquisición de conocimientos sobre el gobierno (ciencia política, teoría de la democracia, estudio de la Constitución Política, etc.), según reza el quinto enunciado enlistado por Abowitz \& Harnish (2006), es nada menos que lo que se ha entendido siempre como "aprendizaje cívico", en el sentido de aquella parte de la educación "que tiene que ver con la adquisición del saber, las destrezas y disposiciones que son necesarios para una buena ciudadanía" (Biesta, 2014, p. 5). Sin embargo, aunque este sea el comienzo incuestionable de cualquier proyecto en educación cívica, se trata de un comienzo desorientador, pues, en primer lugar, ¿cuál ciudadanía podría calificarse de "buena"?, ¿y desde qué criterios se podría evaluar? En segundo lugar, lo que está en cuestión precisamente es lo que se entiende por ciudadanía, ya que, como se ha expuesto, es un conjunto de nociones diversas que no tiene una delimitación única.

En este contexto, para Biesta (2014), la concepción de ciudadanía implica preguntarse por el sentido mismo de la democracia, otro concepto en debate. Siguiendo sobre ello a Rancière (2003), Biesta (2014) especifica que la democracia, más que un orden institucional dado y regido por el 
principio de igualdad, es la disrupción de este en nombre de la misma. En sus palabras, se trata de "la interrupción de un orden social existente con referencia a la idea de igualdad" (Biesta, 2014, p. 4). Es decir, esta interrupción del espacio ordenado políticamente es la presencia misma de la democracia (Rancière, 2003, citado en Biesta, 2014). De este modo, el sujeto político hace aparición como aquel que fuerza con su voz y acción la reconfiguración de lo que ya está previamente ordenado y definido, dislocando los lugares en que cada cual se sitúa, de forma que "hace visible lo que no importaba que fuera visto y hace audible un discurso desde donde no había lugar sino para el ruido" (Rancière, 2003, citado por Biesta, 2014, p. 4).

Considerando estos planteamientos, resulta problemática la "buena ciudadanía", lo que lleva al educador a plantearse una disyuntiva en torno a lo que se propicia por medio del aspecto enunciado como aprendizaje cívico tradicional. Al respecto, es importante problematizar este aprendizaje como socialización o como subjetivación, entendido el primero como reproducción del mismo juego de identidades establecidas y aseguradas, y el segundo como la irrupción de nuevas identidades políticas en los escenarios familiar y escolar.

Como se advierte, el asunto del aprendizaje cívico como dimensión de la ciudadanía asegurada a partir de su propósito (construir un "buen ciudadano") y de su medio (el conocimiento de las disposiciones contenidas en un orden socio-político dado y que el individuo debe adquirir en forma de competencias o directamente como ejercicio) no está desprovisto de problematicidad. Entonces, la construcción de la ciudadanía no se puede subordinar a cuestiones como la pertenencia a un pueblo, la posesión de derechos, la afiliación política o el desarrollo de habilidades y competencias, puesto que es una búsqueda constante, un sueño inacabado de la completitud humana y de emancipación y transformación del sujeto y la sociedad. De ahí la necesidad de iniciar este proceso formativo desde la infancia.

\section{De ciudadanos siervos o de baja intensidad a ciudadanos de alta intensidad}

La historia de la ciudadanía en los países del continente latinoamericano se distancia notablemente del patrón establecido por Karl (2003), pues ha sido un proceso distinto y más complejo. De acuerdo con Rocío Faúndez-García (2006):

[...] mientras en Europa los derechos políticos nacieron y quedaron enraizados en una densa trama de derechos civiles y sociales, en América Latina, donde el estado de derecho en general se conformó bajo democracias 
oligárquicas y excluyentes (O’Donnell, 1999), el componente civil de la ciudadanía nació con una fragilidad que en muchos sentidos parece mantenerse hasta el día de hoy, lo que implica que el sustento básico de igualdad para la efectividad de los derechos políticos nunca ha estado plenamente asentado. (p. 53)

Según Faúndez-García (2006), este proceso de constitución de ciudadanía en América Latina inició con el otorgamiento de derechos sociales (que debido a la globalización neoliberal ha sufrido graves retrocesos), seguido por el reconocimiento de los derechos políticos y luego los civiles. De acuerdo con el politólogo argentino Guillermo O"Donnell (2003), este recorrido conforma un "patrón populista de constitución de derechos" en países como Perú, Argentina, Brasil y México4.

En cuanto al retroceso en los derechos sociales, el filósofo Juan Ramón Capella (1993) advierte que con la globalización neoliberal se han recortado principalmente los de salud, alimentación, vivienda y educación. Además, hay una producción de ciudadanos siervos, constituyéndose como "ciudadanos dotados jurídicamente de derechos, pero desprovistos de la capacidad real y del poder efectivo para ejercerlos plenamente" (p. 151). A ello se suma la despolitización de la población, delegando algunas de las funciones en las cuales debería participar activamente, en la democracia representativa liberal, de modo que esta no encarna los intereses ni las necesidades de la mayoría. Al respecto, Antoni Jesús Aguiló (2009, p. 14) señala que "vivimos en sociedades en las que todas las personas son declaradas formal y jurídicamente ciudadanas con los mismos derechos y deberes y, sin embargo, muchas de ellas, por no decir la mayoría, son tratadas empírica y socialmente como siervas". Es decir, se establece un mundo de relaciones jerárquicas y autoritarias que oprimen y subordinan. Este fenómeno de la globalización neoliberal también ha sido analizado por Boaventura de Sousa-Santos (2005), Ilamándolo fascismo social, definido como "relaciones de poder entre sujetos iguales en teoría, pero radicalmente desiguales en la práctica, caracterizadas por la arbitrariedad y el autoritarismo del elemento fuerte" (p. 14).

En esta misma línea, O’Donnell (1999) advierte sobre la muerte lenta en Latinoamérica de la democracia, caracterizada por el deterioro institucional, la deslegitimación de la política y la obstrucción de los derechos

4 Así mismo, advierte Faúndez-García (2006, p. 54) que "los países del Asia oriental también son ejemplos de otro patrón de constitución de ciudadanía: primero los derechos económicos, sociales y culturales (con un grado alto de extensión y efectividad); luego los políticos; y por último los civiles (O'Donnell, 2003)". 
básicos de los ciudadanos. Ante esta situación la ciudadanía se constituye cada vez más precaria, configurando una ciudadanía de baja intensidad ${ }^{5}$ que pone en riesgo, a su vez, los regímenes democráticos de América Latina. Este tipo de ciudadanía se caracteriza por un respeto a los derechos políticos y un cumplimiento deficitario de los derechos civiles y sociales, de modo que se es un ciudadano con derechos, pero con poca capacidad para ejercerlos, quedando reducido a un elector sin el poder para participar en la toma de decisiones, mientras que otros deciden unilateralmente por él.

\section{Formar para una ciudadanía}

de alta intensidad desde la infancia

derecho: ciudadanos de alta intensidad con capacidad plena para crear y participar directamente en espacios públicos democráticos, estatales y no estatales, que incidan en las decisiones de la función pública y permitan el control social. (p. 18)

En este foco de análisis, se hace necesario incluir una perspectiva feminista y decolonial en la construcción del concepto de ciudadanía, que como hemos visto, es inacabado y se tensiona permanentemente, derivando en interpelaciones para la educación ciudadana frente a sus finalidades, por las demandas sociales que reclaman la creación de mejores condiciones para el ejercicio mismo de la ciudadanía. En este contexto los movimientos sociales han sido el escenario para la aparición de nuevas ciudadanías que reivindican otros mundos posibles y deseables, protagonizados por ciudadanos subalternos por su género, raza, nivel socioeconómico, entre otros,

5 La noción de ciudadanía de baja intensidad fue propuesta por O’Donnell en 1993 a partir de una conceptualización política de democracia en América Latina. Para ampliar información consultar O’Donnell (2003; 2004). 
que demandan transformaciones y una mayor inclusión para "el buen vivir de todas las personas sin exclusión" (Ramos et al., 2020, p. 2109).

Estos citados autores nos proponen una relectura del concepto de ciudadanía a partir de una perspectiva crítica, feminista y decolonial, con el fin de aportar a la formación docente para promover desde la escuela "ciudadanías libres, empoderadas, feministas y descolonizadas" (p. 2106), señalando lo siguiente:

La ciudadanía clásica está construida sobre la base de un sujeto normativo identificado como varón, blanco, heterosexual, de clase media-alta y occidental; todo aquello que se salga de los márgenes de estos atributos sociales y culturales se considera como "lo otro y la otra" y, por lo tanto, se construye por oposición (no hombre blanco, no occidental, etc.) en términos jerarquizados y excluyentes. Dejando por fuera a otros sujetos con sus saberes, experiencias, necesidades, otros cuerpos, otras epistemologías que requieren ser reconocidas y aquí la educación ocupa un lugar fundamental (Ramos et al., 2020, p. 2113).

En esta línea de análisis resultan oportunos los planteamientos de Boaventura de Sousa-Santos (1998; 2004; 2006a; 2006b; 2008), al formular una nueva teoría política de corte crítico y emancipador que propone la reconstrucción crítica de los conceptos de ciudadanía y democracia, y su práctica como eje central, de modo tal que no puede haber una auténtica democracia si no se ejerce una real ciudadanía, enriqueciéndose, a su vez, la democracia representativa liberal establecida. Su concepción de ciudadanía descansa en tres categorías centrales: inclusión pluralista y solidaria, participación política y emancipación social. Esta propuesta de reinvención y práctica emancipadora propuesta por de Sousa-Santos implica una serie de retos y desafíos, planteados por Aguiló (2009), Ramos et al. (2020) y Martínez et al. (2017), que se retoman a continuación, en clave de formación, tanto para los maestros como para las infancias, y que giran en torno a aspectos como el reconocimiento del contexto en el que se inscriben esas acciones formativas; el reconocer y valorar la otredad, lo otro, la otra y su capacidad de agencia; la deconstrucción de roles y estereotipos de género binarios; el señalamiento de algunas dimensiones que demarcan el horizonte formativo y el desarrollo de capacidades para la formación política de los niños, entre otros.

En primer lugar, es necesario vivir y practicar un conjunto de virtudes cívicas, como plataforma para la constitución del sujeto político, caracterizado por la solidaridad, la autonomía, el dijálogo, la razonabilidad, la justicia y la libertad. Un camino para ello son las comunidades de indagación 
con niños ${ }^{6}$, las cuales se fundamentan en el principio de su reconocimiento como interlocutores intelectuales competentes, y pueden constituirse a su vez "en el semillero para la conformación de comunidades justas, puesto que en ellas se encuentran valores ligados al concepto de comunidad, por ejemplo, la conciencia del otro, la colaboración, la seguridad, la participación, la escucha respetuosa y la equidad" (Delgado-Salazar y LaraSalcedo, 2008, p. 680). Pero ese aprendizaje cívico, de acuerdo con Biesta (2016), debemos concebirlo como "subjetivación, como un proceso que no es lineal: no conduce de manera lineal desde un estado de no ser un ciudadano a uno de ser un ciudadano, sino que fluctúa dependiendo de las experiencias ciudadanas reales de las personas y con su participación en experimentos democráticos" (p. 29). Procesos de gran valía, por cierto, porque implican transformaciones personales e identitarias, y no la mera adquisición de una serie de conocimientos y habilidades cívicas para ejercer la ciudadanía.

En segundo lugar, se trata de expandir y ciudadanizar la ciudadanía en el gobierno escolar y otros escenarios de participación, de manera tal que se "construyan y consoliden nuevos espacios de democratización y autonomía, espacios de poder, autoridad y responsabilidad compartida" (Aguiló, 2009, p. 19). Para ello es necesario que los niños aprendan a tomar decisiones, asumir compromisos, resolver sus conflictos, argumentar y regular sus acciones, de acuerdo con las normas establecidas en el aula y en la escuela. Por ejemplo, en nuestro país los centros educativos "Aeiotü" se caracterizan por promover una educación para la ciudadanía de los niños, en la etapa inicial, a través de un enfoque sistémico que aborda sus realidades de manera compleja, mediante relaciones e interacciones que tejen con sus familias, con la comunidad educativa y con la comunidad en general. En este marco, "se reconoce el educar como un proceso de transformación en la convivencia con otro, en ese espacio compartido, en esas relaciones de aceptación e interacción recíproca" (Díaz y Vargas, 2019, p. 95), para que el niño reflexione sobre sus emociones, junto con cómo piensa y actúa en relación consigo mismo y con los demás, rompiendo los diálogos jerárquicos y promoviendo el reconocimiento y la coexistencia en relación con otros modos de ser, estar y comprender el mundo.

En tercer lugar, se debe fortalecer la construcción de ciudadanía desde abajo, para combatir la desigualdad, la discriminación y la opresión, con diferentes proyectos escolares de corte ambientalista, ecologista, pacifista

6 Estas comunidades se desarrollan mediante el programa Filosofía para niños de Matthew Lipman, en el cual aprenden a preguntar, dar y sopesar buenas razones. Algunos de sus libros de trabajo con los niños son: La clínica de los muñecos, Elfie, Pío y Mechas, Harry, Pixxie y Elisa. 
y de defensoría de los derechos humanos y las minorías étnicas y sexuales. Una experiencia la encontramos en "Abracitos Nasa", Ilevada a cabo con setenta niños y niñas víctimas del conflicto armado de las veredas La Selva, El Credo, Pajarito y Los Chorros en el norte del Valle del Cauca (Colombia), que pone de relieve la capacidad de transformar, para dar sentido a las costumbres y tradiciones del territorio mediante la construcción de una iniciativa de memoria colectiva que dignifica la memoria ancestral de sus mayores, incorporando la cosmovisión, los valores y tradiciones culturales, para reescribir la historia de su pueblo luego de la guerra vivida en carne propia. Como proyecto ético, comunitario e integral, podríamos decir que se aproxima a la pedagogía mixe (Arguello, 2016).

Así, a partir de este tipo de proyectos emergen los mundos de la vida, los cuales es vital que los niños comprendan. Como bien lo señalan Alvarado et al. (2016):

Hay entonces que elaborar prácticas de escuela de conformación de un activismo popular que acceda al mundo de lo público, al mundo de los otros y al mundo del "nosotros". Niños y niñas dan muestra de su potencial político y autónomo cuando deciden por el cuidado del otro, aun en un escenario hostil y dramáticamente complejo. (pp. 108-109)

En cuarto lugar, se deberían adelantar prácticas educativas para decolonizar la ciudadanía y reconocer social y legalmente una intercultural, cuya máxima sea "tenemos derecho a ser iguales cada vez que la diferencia inferioriza y a ser diferentes cuando la igualdad nos descaracteriza" (de Sousa-Santos, 2005, p. 84). Estas renovadas expresiones de identidad se construyen sobre la base de unos criterios orientados a alcanzar reconocimiento y mayores niveles de inclusión y equidad en los contextos escolares y sociales, y no caer en el peligro de contar una sola historia (Ngozi, 2009). Para ello se requiere, por parte de los docentes, la necesidad de hacer de las aulas unos laboratorios de ciudadanía, con miras a una educación transformadora y crítica que reconozca la responsabilidad que tiene en la reproducción de desigualdades, y que interpele su capacidad de agencia para la deconstrucción de estas (Martínez et al., 2017).

Por último, se requiere la formación de ciudadanías inconformistas, solidarias y participativas que denuncien, deliberen y sean capaces de formular acuerdos en sus contextos, asumiéndose como agentes de acción política con capacidad de creación para transformar la realidad. En términos formativos, las asambleas de niños, los consejos estudiantiles, la creación de comités y la formulación de pactos son escenarios que promueven el ejercicio de la ciudadanía, pues permiten a los niños emprender acciones 
que favorecen su reconocimiento como actores sociales y solidarios, con capacidades para proponer y transformar sus contextos. Esto exige a su vez repensar los currículos que excluyen la diversidad y naturalizan ciudadanías excluyentes, como también "reconocer la existencia de un currículum oculto que reproduce estereotipos sexistas... contribuye a reproducir las discriminaciones sociales [...] los contenidos, metodologías, sistemas de evaluación, programas de formación docente [...] que reproducen y refuerzan la normalización de las desigualdades" (Martínez et al., 2017, p. 356).

El proceso de globalización que estamos experimentando, las nuevas identidades de género, los movimientos migratorios y las transformaciones sociales y tecnológicas que estamos viviendo, plantean nuevas líneas de investigación en torno a la ciudadanía; en particular, para el campo educativo se requieren más investigaciones acerca de cómo expandirla en la escuela, cómo lograr mayores niveles de inclusión y equidad y qué se requiere para que los adultos reconozcan a los niños como sujetos políticos y como ciudadanos.

\section{A manera de conclusión}

Es fundamental que la escuela posibilite la formación ciudadana desde la infancia, contribuyendo, por medio de acciones desde la vida cotidiana y con espacios curriculares intencionados, a la emergencia de ejercicios formativos políticos para la construcción de sujetos políticos y el reconocimiento de una ciudadanía plena en los niños. De otro lado, la escuela no puede admitir dogmáticamente que las competencias garantizan una ciudadanía conforme a lo que el país y el mundo requieren en la actualidad, o asumir que hay una genéricamente concebida que se construye eficazmente con solo fomentar dichas competencias. Por el contrario, la escuela, y en particular el maestro, están llamados a develar el horizonte conceptual y el entramado axiológico de la formación ciudadana y de la ciudadanía, derivados de sus perspectivas liberal, comunitaria, republicana y emancipadora para nuestro contexto.

Por otra parte, se debe cuestionar el tipo de ciudadanía que se promueve a partir de las iniciativas pedagógicas. Así, es importante determinar si se trata de una ciudadanía como agencia política o como condición legal, de una para siervos o para la emancipación. Además, es necesario problematizar el tipo de ciudadano que se requiere formar hoy en día, ya sea con base en un concepto monolítico de ciudadanía o como un ciudadano en múltiples sentidos: en lo local, como miembro de un Estado nacional; como un ciudadano que reconoce y valora otras ciudadanías posibles o, también, como ciudadano solidario, pero, a la vez, inconformista, que viva 
la ciudadanía como un estilo de vida con alta intensidad, lo que indudablemente requiere de una educación contrahegemónica, transformadora y crítica.

En este sentido, formar desde la infancia para la emancipación de la ciudadanía "no es un objetivo estático, sino dinámico, algo que, como diría el poeta, se hace caminando, que puede entenderse como un recorrido sin término orientado por el proyecto utópico de la democracia sin fin" (Aguiló, 2009, p. 23). Construir ciudadanías de alta intensidad es un camino de luchas y conquistas. Entonces, como dice el poeta, "caminante no hay camino, se hace camino al andar", y su utopía es, en términos de de SousaSantos (1998, p. 340), "una democracia sin fin".

\section{Sobre los autores}

Luz Marina Lara-Salcedo es profesora asociada de la Facultad de Educación de la Pontificia Universidad Javeriana, Colombia, y doctora en Educación de la Universidad Pedagógica Nacional, Colombia. Pertenece al grupo de investigación Formación, Subjetividades y Políticas y coordina la línea Educación para la convivencia escolar y social. Evaluadora del Premio Compartir al Maestro en Ciencias Sociales.

Neftali David Suarez-Rivero es profesor asistente en la Facultad de Ciencias Políticas de la Pontificia Universidad Javeriana, Colombia. Profesor de Derechos Humanos y Teorías de las Relaciones Internacionales. Experiencia en docencia e investigación sobre temas relacionados con filosofía política, resolución de conflictos y estudios de paz.

\section{Referencias}

Abowitz, K. K. \& Harnish, J. (2006). Contemporary Discourses of Citizenship. Review of Educational Research, 76(4), 653-690. https://doi.org/10.3102/ 00346543076004653

Aguiló, A. J. (2009). La ciudadanía como proceso de emancipación: Retos para el ejercicio de ciudadanías de alta intensidad. Astrolabio. Revista internacional de filosofía, (9), 13-24. http://www.ub.edu/astrolabio/Articulos9/DEF/ Aguilo.pdf

Alvarado, S. V., Ospina-Alvarado, M. C. y Sánchez-León, M. C. (2016). Construcción social de la subjetividad política de niños y niñas en contexto de conflicto armado: acción colectiva en la escuela como alternativa de paz. En R. Unda-Lara, L. Mayer y D. Llanos-Erazo. (Coords.), Socialización escolar: procesos, experiencias y trayectos (pp. 101-122). Universidad Politécnica Salesiana/CLACSO/CINDE/Universidad de Manizales. https://www.jstor.org/ stable/j.ctvtxw3k2 
Arguello, A. (2016). Pedagogía mixe: contribuciones para una filosofía (decolonial) de la educación desde las Américas. Estudios Pedagógicos, XLII, (3), 429-447. http://dx.doi.org/10.4067/S0718-07052016000400023

Aristóteles. (1993). Política (Carlos García-Gual y Aurelio Pérez-Jiménez, trad.). Altaya.

Biesta, G. (2014). Learning in Public Places: Civic Learning for the Twenty-First Century. En G. Biesta, M. De Bie, \& D. Wildemeersch (Eds.). Civic Learning, Democratic Citizenship and the Public Sphere (pp. 1-11). Springer.

Biesta, G. (2016). Democracia, ciudadanía y educación: de la socialización a la subjetivación. Foro de Educación, 14(20), 21-34. http://dx.doi.org/10.14516/ fde.2016.014.020.003

Capella, J. R. (1993). Los ciudadanos siervos. Trotta.

Cohen, J. L. (1999). Changing paradigms of citizenship and the exclusiveness of the demos. International Sociology, 14(3), 245-268. https://doi.org/10.1177 /0268580999014003002

Constitución Política de Colombia [Const.] (1991). Artículo 1.

Delgado-Salazar, R. y Lara-Salcedo, L. M. (2008). De la mediación del conflicto escolar a la construcción de comunidades justas. Universitas Psychologica, 7(3), 673-690. https://pdfs.semanticscholar.org/8355/0ea64dcc19eb4c9e b5c0c446c49001856105.pdf

de Sousa-Santos, B. (1998). De la mano de Alicia: lo social y lo político en la postmodernidad. Siglo del Hombre Editores.

de Sousa-Santos, B. (2004). Democratizar la democracia: los caminos de la democracia participativa. Fondo de Cultura Económica.

de Sousa-Santos, B. (2005). El milenio huérfano. Ensayos para una nueva cultura política. Trotta.

de Sousa-Santos, B. (2006a). A gramática de tempo: para una nova cultura política. Afrontamento.

de Sousa-Santos, B. (2006b). Conocer desde el sur: para una cultura política emancipatoria. Programa de Estudios sobre Democracia y Transformación Global.

de Sousa-Santos, B. (2008). Pensar el Estado y la sociedad: desafíos actuales. Conferencias con Boaventura de Sousa Santos. Waldhuter Editores.

Díaz, C. y Vargas, N. (2019). Ambientes, relaciones e interacciones como un tejido sistémico en los momentos cotidianos de aeioTU. Nodos y nudos, 6(46), 13-26. https://doi.org/10.17227/nyn.vol6.num46-8638

Faúndez-García, R. (2006). Ciudadanía de baja intensidad. El aporte conceptual y algunas pistas para su estudio en el caso chileno [Tesis de maestría]. Universidad Santiago de Chile.

Ferrajoli, L. (1999). Derechos y garantías. La ley del más débil. Trotta.

Habermas, J. (1994). Citizenship and National Identity. En B. van Steenbergen

(Ed.). The Condition of Citizenship (20-35). Sage Publications.

Habermas, J. (1999). La inclusión del otro. Estudios de teoría política. Paidós.

Karl, T. L. (2003). América Latina: ciclos virtuosos o perversos. En G. O’ Donnell y J. Vargas (Comp.). Democracia, desarrollo humano y ciudadanía: reflexiones sobre la calidad de la democracia en América Latina (pp. 269-280). Editorial Homo Sapiens. 
Kymlicka, W. y Norman. W. (1997). El retorno del ciudadano. Una revisión de la producción reciente en teoría de la ciudadanía. La Política: Revista de Estudios sobre el Estado y la Sociedad,(3), 5-40.

Leydet, D. (Spring 2014). Citizenship [The Stanford Encyclopedia of Philosophy, electronic version]. Stanford University. http://plato.stanford.edu/archives/ spr2014/entries/citizenship/

Marshall, T. H. (1950). Citizenship and Social Class, and Other Essays. The Syndics of the Cambridge University Press.

Marx, K. (2008). Sobre la cuestión judía. En R. Jaramillo (Ed.), Escritos de juventud sobre el Derecho. Textos 1837-1847 (169-204). Anthropos.

Martínez, I. Ramos, F.J., Sánchez, P. y Blanco, M. (2017). Repensar el concepto de ciudadanía desde la pedagogía feminista para la inclusión de las diversidades en la formación del profesorado. XIV Congreso Internacional de Teoría de la Educación: La educación ante los retos de una nueva ciudadanía. Murcia, España.

Ngozi, C. (2009). El peligro de una sola historia [Conferencia]. http://www.ted. com/speakers/chimamanda_ngozi_adichie.html

O'Donnell, G. (1999). Democratic theory and comparative politics, WZB Discussion Paper, No. P 99-004. Wissenschaftszentrum Berlin für Sozialforschung (WZB).

O’Donnell, G. (2003). Democracia, desarrollo humano y derechos humanos. En G. O’Donnell, O. M. Lazzetta y J. Vargas (Comps.), Democracia, desarrollo humano y ciudadanía. Reflexiones sobre la calidad de la democracia en América Latina (pp. 25-148). Homo Sapiens.

O’Donnell, G. (2004). Notas sobre la democracia en América Latina. En PNUD, El debate conceptual sobre la democracia [Anexo de La democracia en América Latina. Hacia una democracia de ciudadanas y ciudadanos] (pp. 11-82). UN.

Organización de las Naciones Unidas [ONU]. (16 de diciembre de 1966a). Pacto Internacional de Derechos Civiles y Políticos. Adoptado y abierto a la firma, ratificación y adhesión por la Asamblea General en su resolución 2200 A (XXI), de 16 de diciembre de 1966. https://www.refworld.org.es/ docid/5c92b8584.html

Organización de las Naciones Unidas [ONU]. (16 de diciembre de 1966b). Pacto Internacional de Derechos Económicos, Sociales y Culturales. Adoptado y abierto a la firma, ratificación y adhesión por la Asamblea General en su resolución 2200 A (XXI), de 16 de diciembre de 1966. https://www.refworld. org.es/docid/4c0f50bc2.html

Ramos, F. J., Martínez, I. y Blanco. M. (2020). Sentido de la educación para la ciudadanía desde pedagogías feministas, críticas y decoloniales. Una propuesta para la formación del profesorado. Revista Izquierdas, 49, 2103-2126.

Rancière, J. (2003). The philosopher and his poor. Duke University Press.

Walzer, M. (1970). Obligations: Essays on Disobedience, War and Citizenship. Harvard University Press.

Whelan, F. G. (1981). Citizenship and the Right to Leave. The American Political Science Review, 75(3), 636-653. https://doi.org/10.2307/1960958

Zapata-Barrero, R. (2001). Ciudadanía, democracia y pluralismo cultural: hacia un nuevo contrato social. Anthropos Editorial. 